\title{
RETRACTION
}

\section{Retraction: Implications of E-learning systems and self-efficiency on students outcomes: a model approach}

\author{
Tanzila Saba
}

Correspondence: tanzilasaba@ yahoo.com

Faculty of Computer Science and Information Systems, Universiti Teknologi Malaysia, Johor Bahru, Johor, Malaysia
Retraction note - plagiarism

Saba, T. (2012). Implications of E-Learning Systems and Self-Efficiency on Students Outcomes: A Model Approach. Human-centric Computing and Information Sciences, 2(6) doi:10.1186/2192-1962-2-6

It was brought to our attention that the Saba paper did not cite a key source paper: Eom, S. B. (2011). Relationships among E-Learning Systems and E-Learning Outcomes: A Path Analysis Model Human Systems Management, 30(4), 229-241.

In addition there are unacceptable similarities in the data and text appearing in the paper to those published in the abovementioned Eom paper.

This is a violation of publication ethics which according to the Springer Policy on Publishing Integrity warrants a retraction of the article and a notice to this effect to be published in the journal.

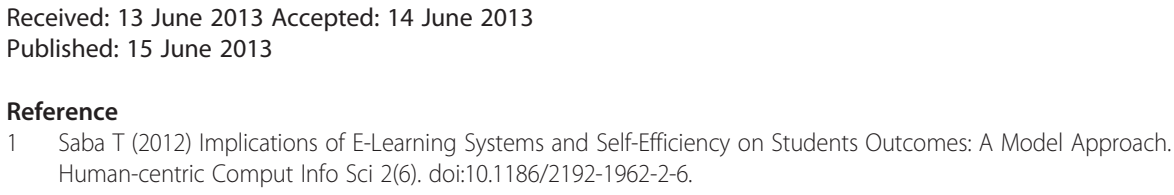

1 Saba T (2012) Implications of E-Learning Systems and Self-Efficiency on Students Outcomes: A Model Approach. Human-centric Comput Info Sci 2(6). doi:10.1186/2192-1962-2-6.

doi:10.1186/2192-1962-3-11

Cite this article as: Saba: Retraction: Implications of E-learning systems and self-efficiency on students outcomes: a model approach. Human-centric Computing and Information Sciences 2013 3:11.

(c) 2013 Saba; licensee Springer. This is an Open Access article distributed under the terms of the Creative Commons Attribution License (http://creativecommons.org/licenses/by/2.0), which permits unrestricted use, distribution, and reproduction in any medium, provided the original work is properly cited. 